\title{
A Modelica Library for Thin-Layer Drying of Agricultural Products
}

\author{
Augusto Souza ${ }^{1} \quad$ Brian Steward $^{1}$ Carl Bern $^{1}$ \\ ${ }^{1}$ Agricultural and Biosystems Engineering, Iowa State University, USA, \\ \{acsouza, bsteward, cjbern\} @iastate.edu
}

\begin{abstract}
Grain drying is highly influenced by environmental and technical factors. Thus, it is essential to track the psychrometric properties of the drying air, besides other grain characteristics, for successful control of this operation. Mathematical modeling of a drying process can be complicated and non-trivial when considering all the involved factors. Based on theoretical differential equations, this study calculates different aspects of grains during their drying process. Modelica and Dymola were used to model blocks of thin-layers of corn, barley, and soybean. The modeled blocks could be used to reproduce a simulation of a grain drying process and keep track of the products moisture content and temperature, besides other psychrometric properties of the air. The developed model has the potential to be used to either to compare to a real grain drying process or as a teaching instrument for grain handling.

Keywords: agriculture, grain drying, Modelica, corn, soybean, barley
\end{abstract}

\section{Introduction}

Moisture content (MC) is an important factor when managing stored grains in agriculture. The amount of water in a agricultural product can determine its value, overall quality, and commercialization. Excess moisture can result in spoilage and insect proliferation. Under improper conditions, stored grain can be a vector of harmful fungi that produce carcinogenic aflatoxins (Christensen and Kaufmann, 1965; Lacey, 1989). Meanwhile, overdried grains result in reduced mass when sold and in wasted drying energy.

Grain drying is a commonly used process to remove water from grains. For commercialization purposes, the USDA assigns grades for grains depending on the quality of the product (USDA, 2013). The amount of damage caused by heat is one of the factors that determine the final grade. Additionally, careless grain drying can decrease grain's' overall quality. Indeed, Wall et al. (1975) showed that corn can lose protein content during drying for temperatures equal or higher than $160{ }^{\circ} \mathrm{C}$. Thus, a negligent control of the drying process can lead to a decrease in grain quality and, consequently, commercial value.

Grain drying is profoundly influenced by different en- vironmental and technical factors. For instance, the psychrometric condition of the heated air will determine the course of the drying process. Thus, it is essential to monitor these thermodynamic and physical properties for successful control of the operation. Additionally, the dehydration of biological material is, likewise, influenced by its chemical composition, actual moisture content, initial conditions, and other aspects. Depending on the type of dryer, the moisture content of the product will be time and space dependent. Thus, it is challenging to predict the exact MC value within this non-linear process (Brooker et al., 1992). Mathematical modeling of a drying process can be non-trivial when considering all the factors involved. Modelica has the advantage of organizing digitally-described components in libraries that can be exported to distinct models and used in different applications. For instance, an encapsulation of grain properties into objects could be used to simulate different drying situations without the necessity of coding and programming.

An early report documented the design of an analog computer for deep-bed drying grain simulation (Baughman et al., 1971). The authors developed equations to calculate moisture content as a function of time and location for dry shelled corn. With this work, an analog computer was able to accurately estimate $\mathrm{MC}$ for the grain. There are more recent examples of modeling and simulating grain drying using different tools and techniques. Khatchatourian et al. (2013) developed software to solve a mathematical model of a cross flow dryer for soybeans. The model was validated using a test stand developed by the authors. The developed model showed a good fit with the validation model, including the energy saved using the cross flowing drying method. However, it would be interesting to see more flexibility in the types of grain used and their drying characteristics. More advanced methods have been used to study the drying process. Azmir et al. (2018) used a combination of computational fluid dynamics (CFD) and discrete element method (DEM) techniques to model and simulate grain drying in a fluidised bed for corn, where the simulation data were consistent with the experimental data. Additionally, Jia et al. (2002) developed computer simulation software to calculate drying for a single grain kernel. According to the study, investigating a single kernel in a bulk of grains can indicate the overall quality of the mass. The authors studied the effects of sev- 
eral variables in different grains using MATLAB 6.0 ®. Although a graphical user interface (GUI) was developed to facilitate use, this software requires a paid license prior to use. It would be difficult to have access to such a tool even for those that can afford it. Modelica has the advantage of being used with open-source software, and with a relative ease of use. Even though it has been used to model different biological or thermal processes (Jain et al., 2017; Aurousseau et al., 2015), few examples exist of its use for agricultural purposes.

Modelica can be used in simulation platforms to design models of dynamic systems. Simulation is used to analyze models and compare the results with what is expected in a real-life situation. Dymola is one platform where Modelica is used to simulate physical models through its libraries. Dymola has the flexibility to change how a system could work by modifying parameters inside each component, how they are connected, and other different conditions.

The objective of this work was to develop a grain drying process model for barley, corn, and soybean by taking into consideration the most relevant aspects that influence the process. Even though soybean is an oilseed, during the course of this paper it is referred as a grain. The Modelica language was used with the Dymola (Version 2017, Dassault Systèmes) environment to create models and packages related to this content. Simulation results were compared to experimental data and the error between these two were calculated. The models could be an agricultural tool for grain monitoring, as well as implemented for didactic reasons for students learning about the drying process.

\section{Methods and System Modeling}

\subsection{Theoretical Modeling of a Thin Layer Drying}

For modeling purposes, grain drying is a thermodynamic process of simultaneous heat and moisture transfer. During this process, air temperature changes as it crosses the layer of grains, as can be observed from Figure 1. Latent heat in the air is transferred to the grain, and at the same time, free water is removed from inside the grains. For this model, the air would flow from the bottom and up through all the grain layers until the exiting at the top.

The humidity ratio is defined as the mass of water vapor per unit mass of dry air. This psychrometric air property is dependent on air temperature and relative humidity. Therefore, during drying, the air moving across the grain layer will remove the moisture, increase the humidity ratio, and, consequently, decrease the capacity of the air to remove water from the grain in the next layer.

The equilibrium moisture content $\left(M_{e}\right)$ of the grain is also dependent on the psychrometric properties of the air. $\mathrm{Me}$ is achieved when the grain internal vapor pressure is equal to the vapor pressure of the environment (Brooker et al., 1992). That is, if the vapor pressure of the environment is less than the vapor pressure inside the prod-

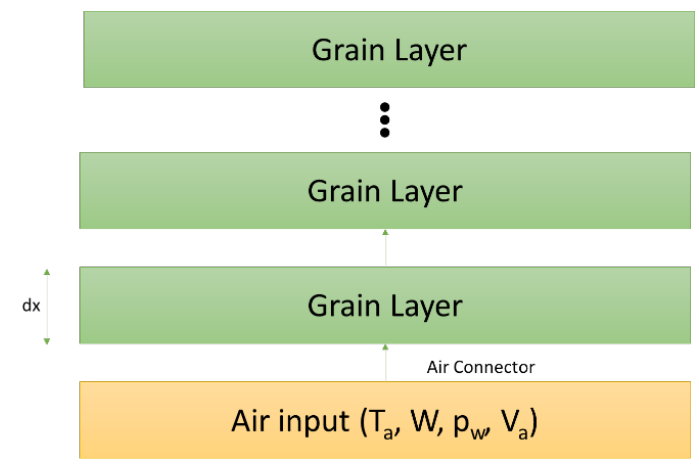

Figure 1. Schematic of the elemental stationary thin layer (thickness $=\mathrm{dx}$ ) connected with other layers

uct, the material will lose (desorb) moisture. When the air is heated, this vapor pressure decreases; however, as the air removes the moisture from the grain, the pressure increases and therefore reduces the drying ratio of the operation.

Differential equations, based on laws of heat and mass transfer, and psychrometric equations, were used according to different sources (Brooker et al., 1992; Pabis et al., 1989). Assumptions are made for a thin layer modeling:

1. The volume shrinkage of the kernels was negligible for the calculations.

2. The temperature gradients for an individual layer were constant.

3. The model did not take into consideration the conduction between kernels.

4. The dryer walls were considered adiabatic and with negligible heat capacity.

5. Empirical and theoretical equations were used for parameter calculation. All these equations were considered accurate.

Four major dynamic variables were calculated in this model as functions of time:

- M - Moisture content of the grain (decimal, dry basis)

- $\mathrm{T}_{p}$ - temperature of the grain $\left({ }^{o} \mathrm{C}\right)$

- $\mathrm{W}$ - humidity ratio ( $\mathrm{kg}$ of water vapor per unit $\mathrm{kg}$ of dry air)

- $\mathrm{T}_{a}$ - temperature of the air $\left({ }^{o} C\right)$

Equations 1 from 4 were used to analyze the grain drying behavior during time of a thin layer. 


$$
\begin{array}{r}
\frac{d M}{d t}=-k \times\left(M-M_{e}\right) \\
\frac{d T_{a}}{d t}=-\frac{h^{\prime} a}{G_{a} c_{a}+G_{a} c_{v} W} \times\left(T_{a}-T_{p}\right) \\
\frac{d T_{p}}{d t}=\frac{h^{\prime} a \times\left(T_{a}-T_{p}\right)+\left[h_{f g}+c_{v}\left(T_{a}-T_{p}\right)\right] \times\left(G_{a} \frac{d W}{d x}\right)}{\rho_{p} c_{p}+\rho_{p} c_{w} M} \\
\frac{d W}{d x}=-\frac{\rho_{p}}{G_{a}} \times \frac{d M}{d t}
\end{array}
$$

Where,

$\mathrm{k}$ - drying constant $\left(h^{-1}\right)$

$\mathrm{M}_{e}$ - equilibrium moisture content (decimals, wet basis w.b.)

h' - convective heat transfer coefficient $\left(J \cdot m^{-2}{ }^{\circ} C^{-1} h^{-1}\right)$

a - particle surface area per unit bed volume $\left(\mathrm{m}^{2} \cdot \mathrm{m}^{-3}\right)$

$\mathrm{G}_{a}$ - air flow rate $\left(\mathrm{kg} \cdot \mathrm{h}^{-1} \mathrm{~m}^{-} 2\right)$

$\mathrm{c}_{a}$ - specific heat of dry air $\left(\mathrm{J}^{\mathrm{kg}} \mathrm{kg}^{-1}{ }^{\circ} \mathrm{C}^{-1}\right)$

$\mathrm{c}_{v}$ - specific heat of water vapor $\left(J . \mathrm{kg}^{-1}{ }^{\circ} \mathrm{C}^{-1}\right)$

$\mathrm{c}_{p}$ - specific heat of dry grain kernels $\left(\mathrm{J} . \mathrm{kg}^{-1}{ }^{\circ} \mathrm{C}^{-1}\right)$

$\mathrm{h}_{f g}$ - heat of evaporation $\left(\mathrm{J} \mathrm{kg}^{-1}\right)$

$\mathrm{dx}$ - layer thickness $(\mathrm{m})$

$\rho_{p}$ - density of the material $\left(\mathrm{kg} \cdot \mathrm{m}^{-3}\right)$

These equations are highly dependent on temperature and moisture differences. The rate at which moisture changes in the mass of grain will depend on its equilibrium moisture content $\left(M_{e}\right)$, which, as the name suggests, will be a point where the grain will be neither losing or absorbing water. This equilibrium is reached depending on the air temperature, relative humidity, and other air temperatures, which are also variables during this dynamic process. Thus, this set of equations physically influence and are dependent of each other.

For this case, the layer of grain was considered thin, in such a way that, the gradient of a variable in a single layer is linear. In other words, the solution of a variable derivative related to the thickness (for example, $d W / d x$ ) would simply be the difference of this variable value in the beginning and at the end of the layer divided by the thickness of the same $(\Delta W / d x)$. With these four essential equations and psychrometric functions, a drying model was designed using the Modelica software.

Moisture Ratio (MR) is calculated using equation 5 and can be interpreted as the portion of water that can still be removed from the grain, using the equilibrium moisture content as a reference. That way, the MR of different grains can be compared independent of the initial moisture content.

$$
M R=\frac{M-M_{e}}{M_{0}-M_{e}}
$$

The model used to calculate the equilibrium moisture content $\left(M_{e}\right.$ in dry basis or d.b.) was the modified Henderson equation solved for $M_{e}$ (Brooker et al., 1992);

$$
1-\frac{P_{v}}{P_{v s}}=e^{-K_{M_{e}}\left(T_{a}+C_{M_{e}}\right)\left(100 \times M_{e}\right)^{N} M_{e}}
$$

Where,

$P_{v}$ - vapor pressure of water $(\mathrm{Pa})$

$P_{v s}$ - saturated vapor pressure of water $(\mathrm{Pa})$

$K_{M_{e}}, C_{M_{e}}, N_{M_{e}}$ - constants associated with equation 6 , as presented in Table 1

Table 1. Constants associated to the Equilibrium Moisture Content Equation

\begin{tabular}{cccc}
\hline Constant & Barley & Corn & Soybean \\
\hline$K_{M_{e}}$ & $2.29 \times 10^{-5}$ & $8.65 \times 10^{-5}$ & $30.53 \times 10^{-5}$ \\
$N_{M_{e}}$ & 2.0123 & 1.8634 & 1.2164 \\
$C_{M_{e}}$ & 195.267 & 49.810 & 134.136 \\
\hline
\end{tabular}

To model the drying process, thermal and physical properties for each grain had to be calculated and this, also, had an influence in the procedure. These properties were equivalent particle radius, specific heat of the product, latent heat of vaporization, grain density, and the product drying constant. Each of these variables had associated constants that were used in empirical models to be calculated. It is beyond of the scope of this paper to list the value of all of them, but they were retrieved from different sources for all the studied grains (Bortolaia et al., 2010; Brooker et al., 1992; Bruce, 1985; Otten and Samaan, 1980).

\subsection{Modelica Models}

The models were developed using the Modelica language. Two main packages were created, Dryer and Grain. The Dryer library contained all the models and classes related to the dryer while the Grain library had the objects modeled associated to the grains and their features.

For the Dryer library, an AirCon connector was created to pass the values for air temperature $\left(T_{a}\right)$, pressure of water vapor $\left(p_{w}\right)$, air humidity ratio $(\mathrm{W})$, and air velocity (Va), as noted in the code:

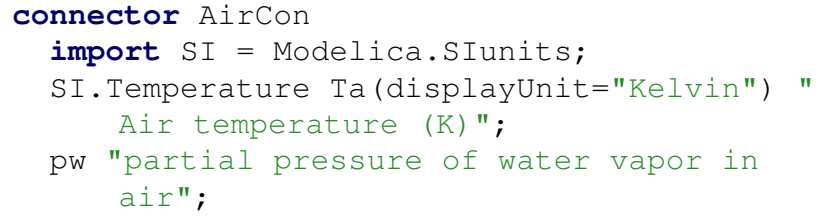




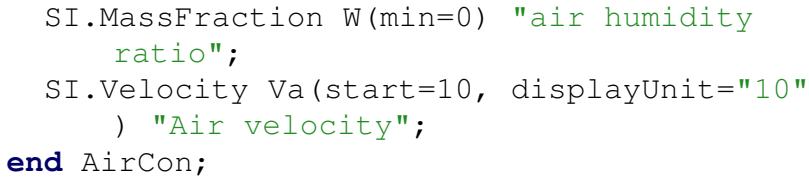

These are features that were used in all the models that required air properties. Also, this connector was used to calculate the psychrometric properties of the air at any point in the drying process. For the Grain library, this same unidirectional-flow AirCon was used for the grains' layers object-model.

Inside the Dryer package was located the Dryer_Input and AirExit models, besides the AirCon connector. Dryer_Input was used to describe the initial conditions of the dryer. It was possible to input the initial air temperature $\left({ }^{\circ} \mathrm{C}\right)$, the drying temperature $\left({ }^{\circ} \mathrm{C}\right)$, initial relative humidity (\%), dryer diameter (meters), and air velocity $(\mathrm{m} / \mathrm{sec})$.

For each grain, a Layer model was designed inside the Grain Package, which contained the variables and constants associated with the grain. Each Layer had two AirCon connectors for the air input and output. The connector at the exit of the layer could be linked to the next layer. Thus, the air that leaves the first layer would be used to dry the second one. The initial thickness (m) and MC (decimal, w.b.) of the grain layer could be logged in this model.

A dryer operation simulation contained a stack of thinlayers, modeled in Dymola, attached to the air input, as observed in Figure 2. The layers were connected in such manner that the air used in the first layer would exit and enter the second layer with different psychrometric properties; thus, having the properties after the air removes moisture from the initial layer. At the end, the final psychrometric properties were calculated in the developed Output class. This class represents the exit of the dryer and it could be used to observe the psychrometric properties of the exiting air.

The time unit used for the simulation was seconds, even though the results are reported in hours. This distinction is important to emphasize because the simulation steps are based on this unit and conversions should be made convenient for the involved variables. The International System of Units (SI) was used for all other units using the Modelica Standard Library.

Different scenarios were simulated to test the model. Three thin layers of the studied grains were dried under the same conditions and duration. The initial moisture content was $35 \%$ (w.b.) and the layer was 0.25 meters thick. The grain temperature was originally at $25^{\circ} \mathrm{C}$, and the drying air temperature was $70^{\circ} \mathrm{C}$ for this simulation. The relative humidity of the air, before entering the Dryer, was set as $50 \%$. The drying duration was two hours and the simulation used the Dassl algorithm (tolerance $=0.0001$ ) to find the solution for this model. Additionally, fifty thin layers, with a thickness of 0.25 meters each, were stacked, representing the drying of a deep bed column of 12.5 meters of grain. The simulation had a duration of 10 hours. The outside air was set to a temperature of $30{ }^{\circ} \mathrm{C}$ and relative humidity of $50 \%$. Also, the effect of three different temperatures were investigated for thin layers of corn. Three layers of corn, with an initial product temperature of 15 ${ }^{\circ} \mathrm{C}$, were modeled at three different temperatures $(25,50$, and $90^{\circ} \mathrm{C}$ ) during a drying period of 3 hours.

To validate this model, the simulation results were compared to different experimental values using similar characteristics of the designed model results (Table 2). For instance, all the works consulted used thin layers of grains in static beds at different temperatures (Markowski et al., 2010; Li and Morey, 1984; Freire et al., 2005).

\section{Modeling Outcome and Simulation Results}

The two main components modeled were the grain layers models and the air input ("Grain"Layer and Dryer_Input). Some of the parameters for both components would take default values if not specified by the user. For the Dryer_Input component, the inputs needed were Outside Air Temperature $\left(T_{0}\right)$, desirable Drying Temperature $\left(T_{a}\right)$, Relative Humidity $(R H)$, Bin Diameter $(D)$, and Air Flow Velocity $\left(V_{a}\right)$. All these were parameters of the Dryer_Input component. The CornLayer component needed three inputs: Thickness of the grain layer $(d x)$, Initial MC $\left(M_{0}\right)$, and Initial Temperature of the Product $\left(T_{p}\right)$.

Table 2. Experimental data collected for comparison

\begin{tabular}{cccc}
\hline Parameters & $\begin{array}{c}\text { Barley (Markowski } \\
\text { et al., 2010) }\end{array}$ & $\begin{array}{c}\text { Corn (Li and Morey, } \\
\mathbf{1 9 8 4})\end{array}$ & $\begin{array}{c}\text { Soybean (Freire et al., } \\
\text { 2005) }\end{array}$ \\
\hline Initial Moisture Content (\%, w.b.) & 17.5 & 26 & Results in Moisture Ratio \\
Layer Thickness (mm) & $333.0 \pm 5.0$ & 5.91 & 27.0 \\
Air velocity $(\mathrm{m} / \mathrm{s})$ & $30.1 \pm 0.1$ & 0.3 & 1.75 \\
Initial Air Temperature $\left({ }^{\circ} \mathrm{C}\right)$ & $33,41,48$, and $56 \pm 2$ & $27,49,71,93$, and 116 & $31.5,45$, and 58.5 \\
Initial Product Temperature $\left({ }^{\circ} \mathrm{C}\right)$ & Around 10 & Room temperature & Close to air temperature \\
Drying duration (hours) & 3 & 10 & 6.666 \\
Initial RH $(\%)$ & \pm 35 & - & - \\
\hline
\end{tabular}


The first two were parameters of the model, while the last one was considered as a variable since it changes with time as it exchanges heat with the air.

\subsection{Thin-layer models}

The drying of thin layers was simulated for each grain studied in parallel (Figure 3(a)). Although Figure 3 shows the source of hot air from the same dryer, there was no separation in the flow of air in the simulation; they all had the same input air properties from the Dryer_Input block.

The change in the Moisture Ratio (MR) was observed for the three grains (Figure 3(b)). At the end of the simulation, the final MR value for corn was $0.319,0.300$ for soybean, and 0.074 for barley, thus, the latter had a faster drying rate compared to corn and soybean at $70{ }^{\circ} \mathrm{C}$. This difference is expected since the grains have different properties based on their chemical compositions and physical characteristics that influence the exchange of water with the air. However, for this example, two hours was not enough to completely dry the grains or reach a steady state on the MR.

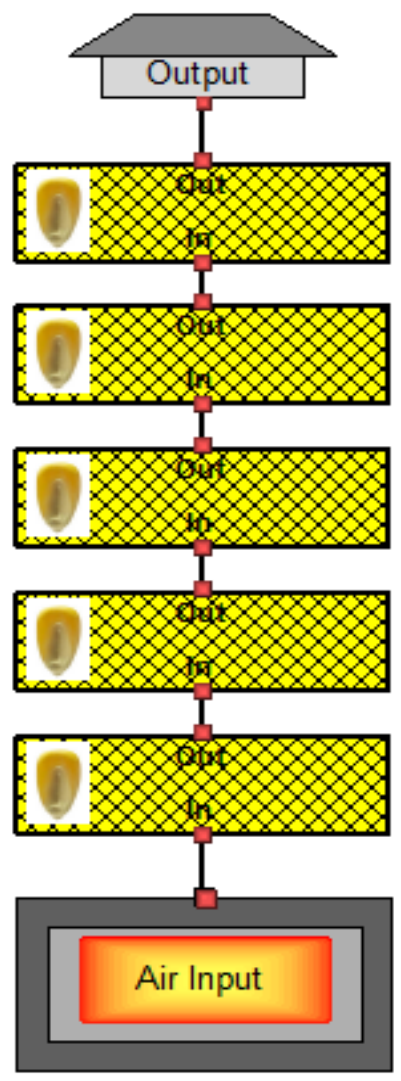

Figure 2. Example of stacked thin corn layers blocks attached to the Dryer_Input and Air_Exit blocks

\subsection{Deep bed simulation for corn}

The MR was similar at the beginning of the drying; however, the difference between the layers increased as the drying continued, as observed in Figure 4. At the end of the simulation, the difference between the moisture content of the grains in the first and last layers was of 2 percentage points. This demonstrates that, when the air crossed the last layer, it was already carrying moisture from the other layers, which decreased the capacity of the air to remove water from the grains at the end of the dryer. Comparing the the humidity ratio (HR) during the time for these two layers, reiterates how the air was filled with moisture and had its drying capacity reduced at the end of the grain column (Figure 5). While air travels through the column of grain, it absorbs water vapor from the grains and increases its HR. As expected, the humidity ratio was higher at the beginning of the drying simulation and decreased over time since the grain had less water to be absorbed. The changes for HR over time for the first layer are less perceptible compared to the last one, indicating that the humidity ratio exiting the last layer is clearly higher than the first layer's HR.

An AirSensor component was connected after the last layer of the deep-bed simulation to measure the psychrometric properties of the air. Figure 6 shows three air properties at the exit of the dryer: saturated $\left(p_{w s}\right)$ and partial $\left(p_{w}\right)$ pressure of water vapor, and Relative Humidity (RH). It can be observed that the $p_{w s}$ was nearly constant $(4.23 \mathrm{kPa})$ during the simulation, which means the air was fully saturated with water vapor at the exit of the last layer for the entire drying time. Meanwhile, the $p_{w}$ had an increase before descending until the end where it reached a final value of around $1.90 \mathrm{kPa}$. That is, the water vapor molecules were exerting less pressure in moist air. This can be associated with the removal of moisture from the grains with time and less free water for the dry air to absorb. RH is the ratio of water vapor in the air and the pressure when it is saturated, i.e., it can be expressed in terms of $p_{w} / p_{w s}$. Similarly to the $p_{w}$ trend, the RH had a sudden raise before decreasing, as observed in Figure 6. The final value for RH was 0.449 , corresponding to the ratio $p_{w} / p_{w s}$ at the end of the simulation.

\subsection{Temperature Comparison}

The air temperature has a significant role during the drying process of biological materials. It will affect the rate of the process and the equilibrium moisture content of the product, as observed from Equations 1 to 4, and 6. The simulation results for MC are illustrated in Figure 7. As expected, the higher the air temperature, the faster the grain dried. The layer of corn reached MC of less than $5 \%$ in three hours, under air temperature of $90{ }^{\circ} \mathrm{C}$. Meanwhile, the layer with the same characteristics, but with the air temperature at $25{ }^{\circ} \mathrm{C}$, achieved a final $\mathrm{MC}$ value around $15 \%$. Even though the models results were consistent with what was predicted, the simulation results needs to be val- 


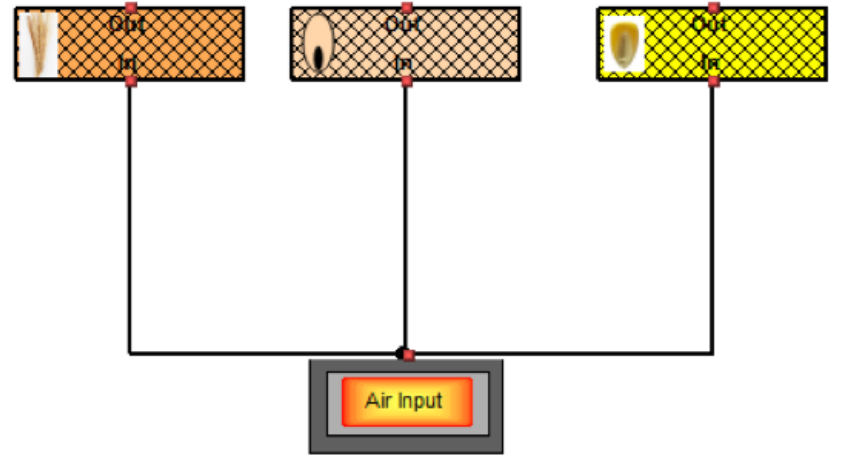

(a)

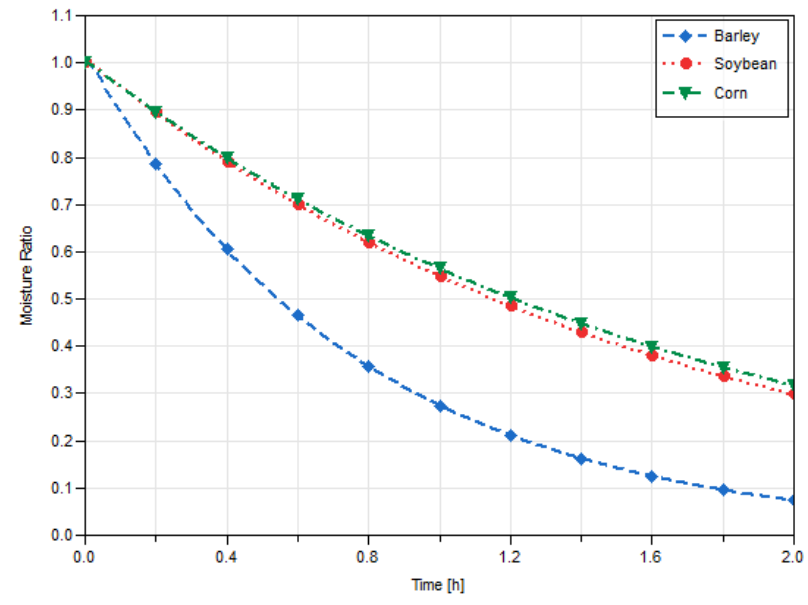

(b)

Figure 3. Thin layers connected to the dryer (a) and Simulation results (b) for Barley, Soybean, and corn

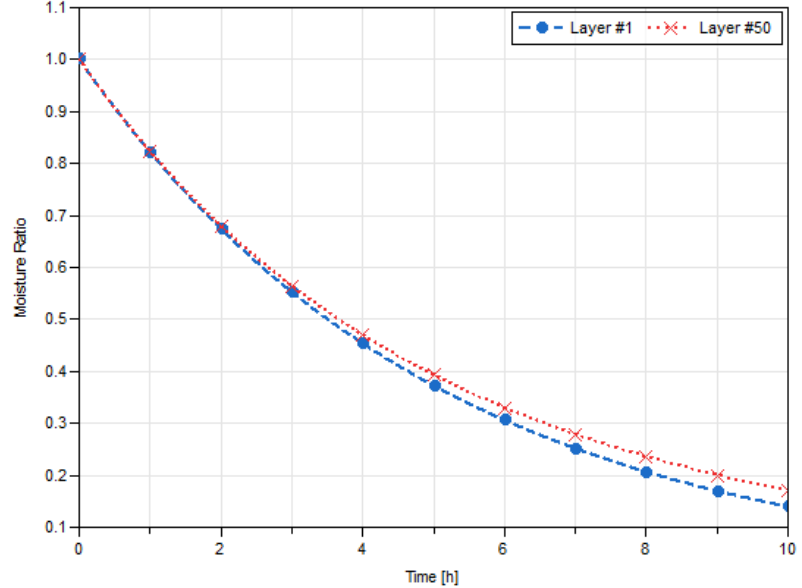

Figure 4. Moisture Ratio over time for the first and last layer of a deep bed simulation

idated with experimental results to verify the precision of the Modelica library.

There is an extensive discussion about the use of high temperatures for faster drying over the risk of losing grain quality due to heat damage or loss of dry mass. This could be used as a comparative tool to real situations to make the best decisions about the amount of time for the grain to dry.

\section{Model Validation}

The simulated results were compared to experimental data from different sources for each of the grains studied (Markowski et al., 2010; Li and Morey, 1984; Freire et al., 2005). The products features and the characteristics of the drying process are shown in Table 2. The reason why these studies were chosen was because they had similar characteristics to the designed Modelica library, such as a broad temperature range, thin-layer of grains, and complete de-

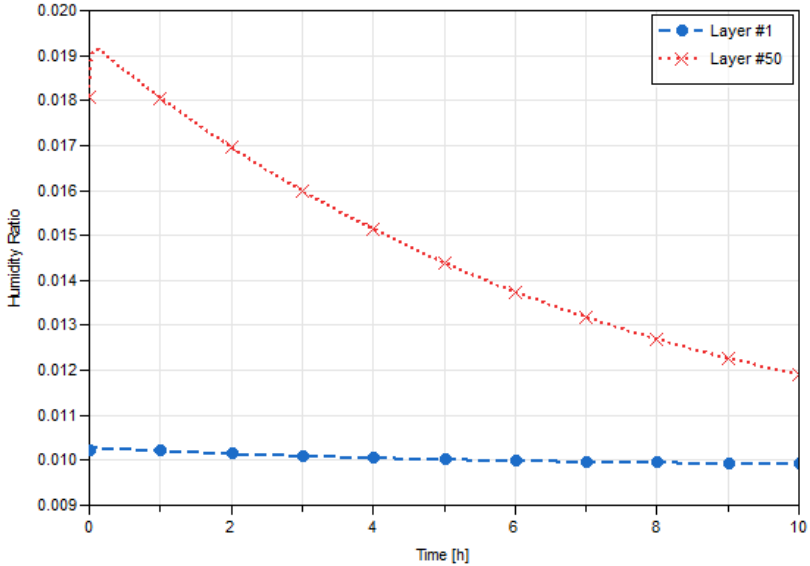

Figure 5. Humidity Ratio $(\mathrm{m} / \mathrm{m})$ at the exit of the first and last layer over time for the a deep bed simulation

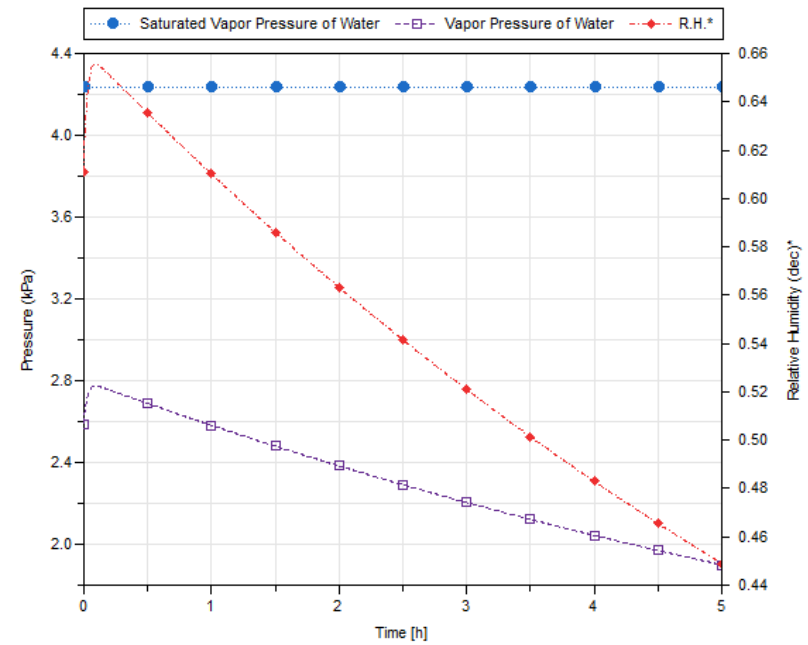

Figure 6. Saturated and partial Water Vapor pressure (left axis), and Relative Humidity (right axis) of the air at the dryer exit 


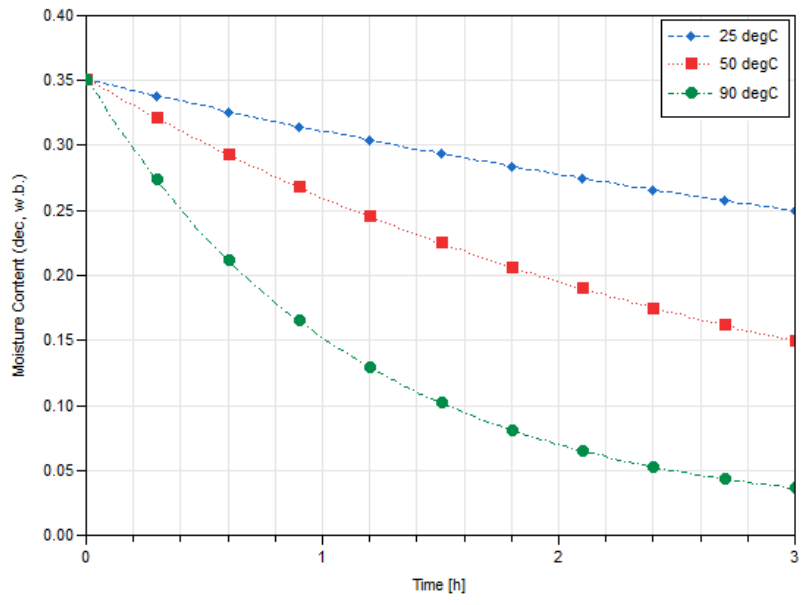

Figure 7. Moisture content for thin corn layers at different drying temperatures

scription of the utilized drying process.

The Modelica results compared to the experimental data from different studies can be seen in Figure 8. The experimental data are similar to the simulated results. In general, they followed the same drying trend, but they did not have the exact final value. While the results for barley and soybean are in Moisture Ratio (Figure 8 (a) and (c)), the results for corn were reported in terms of the product Moisture Content (Figure 8(b)). To avoid misleading and erroneous interpretation, the simulation results were reported using the variable as the extracted experimental data.

There are some differences that can be attributed to variations in grain composition, drying management, and final moisture determination. For example, different varieties of the same grain have distinct shapes that influence the drying rate. Similarly, the drying geometry and method vary and may affect the final moisture content. Additionally, error accumulates during time of both data; thus, the final MR or MC value is impacted by the error of the entire process. Table 3 shows the mean squared error (MSE), the average relative error (RE), and the relative error for the final moisture content or moisture ratio of the drying between the experimental and simulated data. It can be observed from this table that the lowest relative error for corn, barley, and soybean were respectively at 48 , 27 , and $31.5{ }^{\circ} \mathrm{C}$. Nearly the same is applied to the final $\mathrm{RE}$, the exception is corn at $93^{\circ} \mathrm{C}$. For the MSE, the min- imum values were at 48,93 , and $58.5^{\circ} \mathrm{C}$ for barley, corn, and soybean, respectively. Between all grains, barley had the lowest values; thus, the Modelica model could estimate moisture better for this grain. The final RE is biased since the error is accumulated from the beginning of the simulation. In general, this value was higher than the average RE ( 9 out of 12 cases), which showed how the error was carried along during the simulation.

It is difficult to validate the model with so many variables to control. These differences could reflect in the difference between experimental and simulated data. Additionally, there are parameters that depend on grain chemical composition that can change depending on the variety of the product. For example, some corn kernels with less protein and more starch content could have different drying curves. Also, more experimental data could be obtained to recalibrate some empirical parameters for the grains used. Also, experimental data could optimize the model to achieve better results from the simulations. However, every new grain variety, with different composition and geometry, could lead to distinct sets of constants to be used in mathematical modeling of a drying process.

\section{Conclusion and Future Work}

Several Modelica components were modeled to simulate the grain drying process. Barley, corn, and soybean were studied to be used on this model, where the simulation results were compared to experimental data from different sources. There were some differences between these two types of data that can be attributed to differences in grain composition, controlling the drying environment, and errors associated with using some outdated empirical parameters. Even though Dymola was used for modeling and simulation, the library can be used with other opensource environments for Modelica. Overall, this Modelica library could be an educational accessory to learners interested in this topic.

This library can be further expanded to simulate more grains and other agricultural products. Likewise, for this study, only a fixed-bed dryer was simulated; thus, a variety of dryers could be added to this set of components to broad its use. Some additional capabilities could be added such as variable weather circumstances and mold controlling through grain and air conditions. The Modelica capabilities to be applied to agriculture are abundant, and it has great potential to be further explored.

Table 3. Mean squared error and average relative difference between experimental and simulation data for the three grains

\begin{tabular}{l|cccc|ccccc|ccc}
\hline & \multicolumn{7}{|c}{ Barley } & \multicolumn{7}{c}{ Corn } & \multicolumn{3}{c}{ Soybean } \\
\hline Temperature $\left({ }^{\circ} \mathrm{C}\right.$ ) & 33 & 41 & 48 & 56 & 27 & 49 & 71 & 93 & 116 & 31.5 & 45 & 58.5 \\
\hline MSE (dec. ${ }^{2}$ or \% ${ }^{2}$ ) & 0.0026 & 0.0033 & $5.21 \mathrm{e}-4$ & 0.0020 & 1.09 & 4.40 & 1.37 & 0.186 & 0.982 & 0.0050 & 0.0037 & 0.0027 \\
Average R.E. $(\%)$ & 8.57 & 12.1 & 5.91 & 15.6 & 5.86 & 22.7 & 21.1 & 7.03 & 17.9 & 9.38 & 17.6 & 21.3 \\
Final R.E. $(\%)$ & 12.4 & 24.9 & 8.53 & 24.2 & 8.32 & 54.5 & 56.8 & 0.33 & 8.21 & 6.15 & 37.5 & 48.2 \\
\hline
\end{tabular}




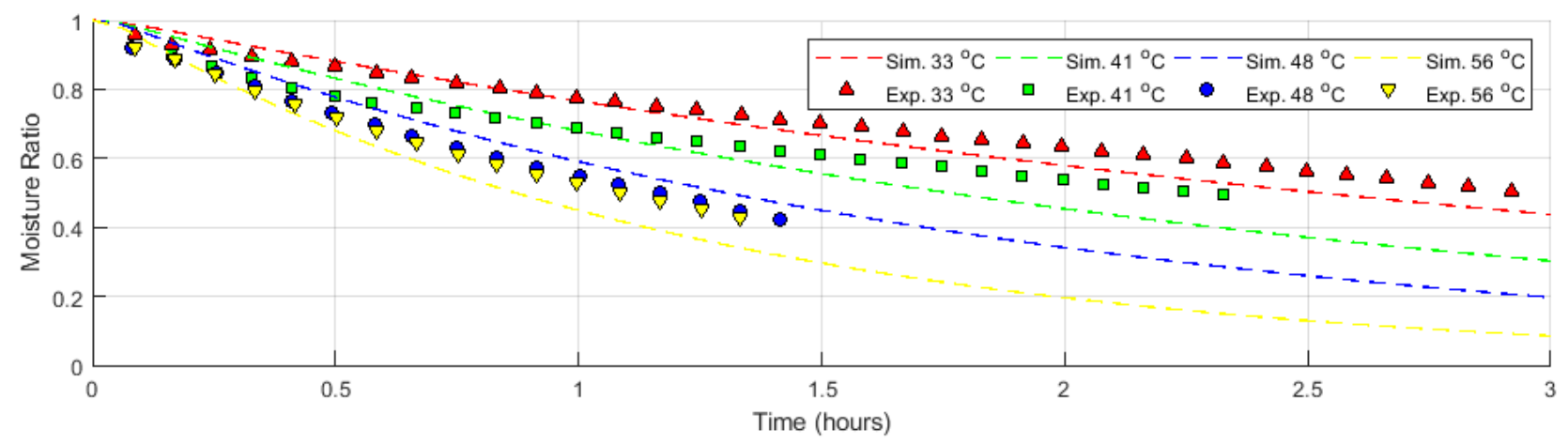

(a)

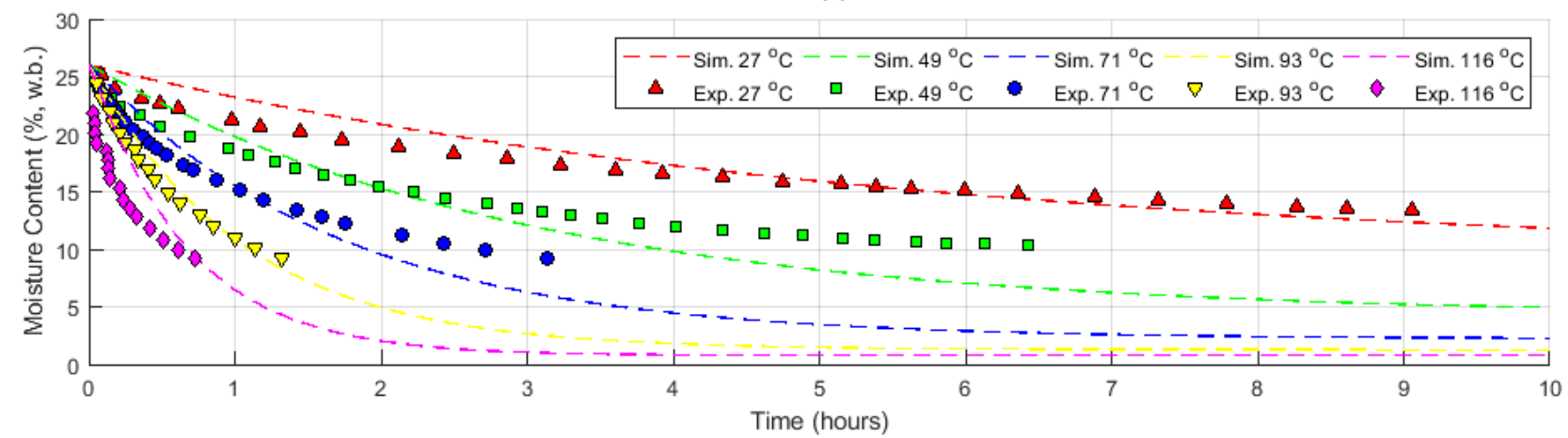

(b)

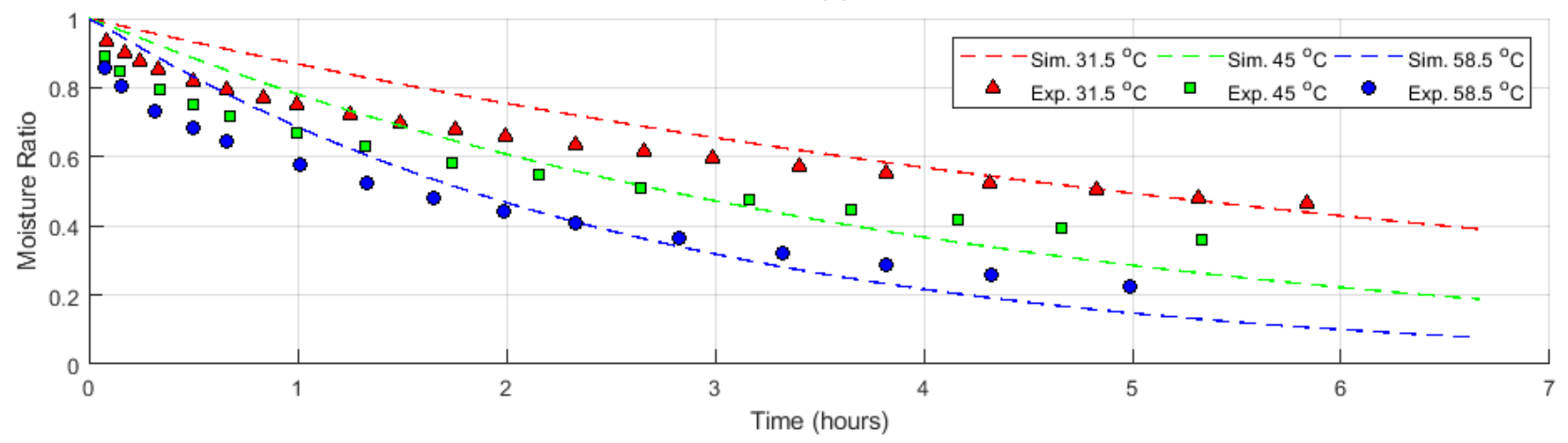

(c)

Figure 8. Results comparison between experimental and simulation data for Barley (a), Corn (b), and Soybean (c) 


\section{References}

Antoine Aurousseau, Valery Vuillerme, and Jean-Jacques Bezian. Modeling of Linear Concentrating Solar Power using Direct Steam Generation with Parabolic-Trough. pages 595-603, 9 2015. doi:10.3384/ecp15118595. URL http://www.ep.liu.se/ecp/article.asp? issue $=118 \% 26 \operatorname{article}=64$.

Jannatul Azmir, Qinfu Hou, and Aibing Yu. Discrete particle simulation of food grain drying in a fluidised bed. Powder Technology, 323:238-249, 2018. ISSN 1873328X. doi:10.1016/j.powtec.2017.10.019. URL https://doi . org/10.1016/j.powtec.2017.10.019.

G. R. Baughman, M. Y. Hamdy, and H. J. Barre. Analog Computer Simulation of Deep-Bed Drying of Grain. Transactions of the ASAE, 14(6):1058-1060, 1971. ISSN 2151-0059. doi:10.13031/2013.38452. URL http: / /elibrary . asabe.org/abstract . asp? ? JID $=3 \& A I D=38452 \& C I D=t 1971 \& V=14 \& i=6 \& \mathrm{~T}=1$.

Luis A. Bortolaia, Oleg Khatchatourian, and Horacio A. Vielmo. Analysis of soybean drying dynamics in thin layer. 13th Brazilian Congress of Thermal Sciences and Engineering December 05-10, 2010, Uberlandia, MG, Brazil, 2010.

Donald B. Brooker, Fred W. Bakker-Arkema, and Carl W. Hall. Drying and storage of grains and oilseeds. Van Nostrand Reinhold, 1992. ISBN 9780442205157. URL http:// www.springer.com/us/book/9780442205157.

D.M. Bruce. Exposed-layer barley drying: Three models fitted to new data up to $150^{\circ} \mathrm{C}$. Journal of Agricultural Engineering Research, 32(4):337-348, 12 1985. ISSN 0021-8634. doi:10.1016/0021-8634(85)90098-8. URL https://www.sciencedirect.com/science/ article/pii/0021863485900988.

Clyde M. Christensen and H. H. Kaufmann. Deterioration of Stored Grains by Fungi. Annual Review of Phytopathology, 3(1):69-84, 9 1965. ISSN 0066-4286. doi:10.1146/annurev.py.03.090165.000441. URL http://www.annualreviews.org/doi/10. $1146 /$ annurev.py.03.090165.000441.

Fabio B. Freire, Marcos A.S. Barrozo, Dermeval J.M. Sartori, and Jose T. Freire. Study of the drying kinetics in thin layer: Fixed and moving bed. Drying Technology, 23(7):14511464, 2005. ISSN 07373937. doi:10.1081/DRT-200063508.

Rahul Jain, Kannan M. Moudgalya, Peter Fritzson, and Adrian Pop. Development of a Thermodynamic Engine in OpenModelica. pages 89-99, 7 2017. doi:10.3384/ecp1713289. URL http://www.ep.liu.se/ecp/article. asp?issue $=132 \% 26$ article $=009$.

C.-C. Jia, W. Yang, T. J. Siebenmorgen, and A. G. Cnossen. Development of Computer Simulation Software for Single Grain Kernel Drying, Tempering, and Stress Analysis. Transactions of the ASAE, 45(5):1485-1492, 2002. ISSN 2151-0059. doi:10.13031/2013.11039. URL http://elibrary.asabe.org/abstract.asp? ? JID $=3 \& A I D=11039 \& C I D=t 2002 \& V=45 \& i=5 \& T=1$.
O. A. Khatchatourian, H. A. Vielmo, and L. A. Bortolaia. Modelling and simulation of cross flow grain dryers. Biosystems Engineering, 116(4):335-345, 2013. ISSN 15375110. doi:10.1016/j.biosystemseng.2013.09.001. URL http: //dx.doi.org/10.1016/j.biosystemseng . 2013.09 .001 .

J. Lacey. Pre- and post-harvest ecology of fungi causing spoilage of foods and other stored products. Journal of Applied Bacteriology, 67:11s-25s, 12 1989. ISSN 00218847. doi:10.1111/j.1365-2672.1989.tb03766.x. URL http://doi.wiley.com/10.1111/j. 1365-2672.1989.tb03766.x.

Huizhen Li and R Vance Morey. Thin-layer drying of yellow dent corn. Transactions of the ASABE, 27(2):581-585, 1984. ISSN 00012351. doi:10.13031/2013.32832. URL http://elibrary.asabe.org/abstract.asp? aid $=32832 \& t=3$.

Marek Markowski, Ireneusz Białobrzewski, and Agnieszka Modrzewska. Kinetics of spouted-bed drying of barley: Diffusivities for sphere and ellipsoid. Journal of Food Engineering, 96(3):380-387, 2 2010. ISSN 02608774. doi:10.1016/J.JFOODENG.2009.08.011. URL https://www.sciencedirect.com/science/ article/pii/s0260877409004099?via\%3Dihub.

Lamber Otten and George Samaan. Determination of the Specific Heat of Agricultural Materials: Part II. Experimental Results. Canadian Agricultural Engineering, 22(1):25-27, 1980.

S. Pabis, D. S. Jayas, and S. Cenkowski. Grain Drying: Theory and Practice. John Wiley and Sons Ltd, New York, United States, 1989. ISBN 0471573876.

USDA. Grain Inspection Handbook - Book II. Washington, DC, 2013. URL https://www.gipsa.usda.gov/fgis/ handbook/BK2/BookII4-11-2017.pdf.

J.S. Wall, C. James, and G.L. Donaldson. Corn proteins: chemical and physical changes during drying of grain. Cereal chemistry, v. 52(no. 6):779-790, 1975. 